\title{
Bioethics Education in Africa: Still Complex Challenges
}

\author{
Cletus T. Andoh \\ Department of Philosophy, University of Yaounde I, Yaounde, Cameroon \\ Email: actandoh@justice.com \\ Received May $7^{\text {th }}, 2013$; revised June $5^{\text {th }}, 2013$; accepted June $15^{\text {th }}, 2013$
}

Copyright (C) 2013 Cletus T. Andoh. This is an open access article distributed under the Creative Commons Attribution License, which permits unrestricted use, distribution, and reproduction in any medium, provided the original work is properly cited.

\begin{abstract}
In recent times, bioethics has emerged as a burgeoning interdisciplinary field of scholarly investigation which has in the past decades migrated from bedside consultations to public policy debates and wider cultural and social conversations that privilege all discourse about everyday life issues. Today, bioethics is increasingly seen as a field departing from a multi-disciplinary perspective to an autonomous discipline. In most Western countries, the field is now more organized, complete with undergraduate minors and majors, and even high school courses in bioethics, master's degrees and doctoral programs, and professional associations. Also, there is a shift from a field populated by bioethics pioneers to a field made up of bioethics professionals. However, in Africa the emergence and evolution of the field is still problematic as bioethics is not yet an escalating discipline in the tradition of books, journals, classroom teachings and conferences. In this paper, it is argued that the lack of an authentic discourse on the nature and contents of bioethics, interdisciplinary research approaches, institutional and infrastructural needs and a critical mass of African experts constitutes the major challenges to the teaching of bioethics in Africa. There is a need to reinvigorate standards for teaching bioethics through a radical critique of traditional values, principles, methods and a careful assessment of the new megatrends and challenges in science, technology and medicine.
\end{abstract}

Keywords: African Bioethics; Bioethics Education; Critical Thinking; Empirical Research; Ethics Expertise; Interdisciplinary Research; Medical Ethics; Turning a Blind Eye

\section{Introduction}

The new advances in science and the megatrends in healthcare management and delivery are irrevocably transforming the nature and content of bioethics. As new innovation in science increasingly transforms human wellbeing, concerns about its applications are increasingly under serious scrutiny as there is increasing awareness of the ambivalence of scientific development. These advances in science are creating moral questions that challenge accepted ethical thinking and require urgent answers. Also, confronted with these advances, traditional modes of understanding and teaching bioethics are proving incommensurable with new developments and the dilemmas created. This imposes the need for more critical and radical approaches to the teaching of bioethics in Africa, as citizens will need to make important decisions that affect their lives and society as a whole.

Furthermore, academic bioethics programs have proliferated Western universities and bioethics has been institutionalized as an integral part of mainstream education in academia and the task of teaching bioethics has increasingly become inescapable. Bioethics education within Africa is still sub-marginal and insufficient due to the fact that it is not yet an escalating discipline in the tradition of books, journals, classroom teachings and conferences. The field has not yet had any considerable recognition and penetrance in academia as it is not yet a vibrant field in terms of scholarly presentations, publications and learning in academic institutions and educational system in Africa.
There is an insufficient scholarly intellectual recognition of the field in Africa as no major steps are being undertaken to institute and initiate the teaching of bioethics in schools and universities. Bioethics is yet to be recognized by most African governments as a legitimate field of scholarly investigation.

Added to the forgoing, there is greater recognition and routinization of the field's proactive and critical stance in the academia, the polity and the media in Western countries. In Africa, bioethics is not yet proactive but has remained diminishingly reactive, corrosive and evanescent as it is not yet institutionalized and legitimized in academia. There are no experts or trained professional bioethicists in Africa to support the production of high quality journal articles and there are almost no published books on bioethics by African scholars that can encourage the development and production of research within the continent. A critical investigation of the status of bioethics in Africa reveals that bioethics education and ethical concerns have unwittingly been unrecognized, downplayed or overlooked by local governments in Africa for the past fifty to sixty years of its existence. This situation is unacceptable considering the fact of the influence of bioethics as the most important field that serves and protects the wellbeing of humanity. Its impact on the lives of Africans and the future of bioethics education in Africa is characterized by ambiguity and uncertainty. Africans are increasingly confronting bioethics issues without sufficient expertise and this imposes the needs for new and critical approaches to bioethics education to raise students' awareness and enable African scholars to assess these advances in an ethical 
manner. This need is of utmost urgency for Africa today since we need to recreate ethical life and standards.

\section{Methodological and Interdisciplinary Research Challenges}

Bioethics has now evolved to an interdisciplinary field of scholarly investigation on every aspect of life, and this transforms it into a disparate discipline that uses different methods and approaches. As new scientific innovations moves forward introducing complex challenges or sophisticated problems, the need for an expansion and broadening of the scope and horizon of bioethics became acute requiring inputs from different experts from various disciplines. As interdisciplinarity becomes fundamental in bioethics attracting different practitioners, there is conceptual boundary crossing and crosstalk as the borderlines and intersection between the human, social and exact sciences are blurred. In this current context, research and decision making becomes complex due to the methodological convergence or the synergistic combination of empirical and theoretical methods to investigate facts and beliefs. Interdisciplinary research is a reality on most campuses of Western universities as academic bioethics programs proliferates these institutions and this creates the challenge to know if this burgeoning teaching approach to education is possible within Africa and if not what is required to enable bioethics education in this form develops.

Bioethics is complex and multifaceted, drawing on philosophy and law as well as science and medicine (Schaller, 2008). Many bioethical works express what seems to be a rather worthy objective, notably, of investigating ways of making people better or making better people. Conceivably, this invites a pretty broad approach to the question of how we achieve greater health, happiness, and the living of the good life (Priaulx, 2011). Initially, works in bioethics used a normative analysis of bioethical issues, arguing for or against the moral permissibility of a particular technology, practice, or policy. Around the 70s, physicians and lawyers became involved and started making normative claims about bioethical issues. But by the mid $90 \mathrm{~s}$, bioethics attracted scholars from varied disciplines, among which were social scientists and empirically trained clinicians, both physicians and nurses and this transformed the "methods" of bioethics. Much bioethical work today has taken "an empirical turn," featuring social scientific perspectives on relevant issues and behaviors.

The shift of bioethics research from normative analysis to empirical study is not in order to curtail the former, but rather to make the field more practically based in the generation, presentation and analysis of its vital evidence. In this approach the gap between normative and empirical analysis become an artificial one. The boundaries between them are blurred in much of the relevant work as they share interests in the conceptual, cultural, political and practical aspects of the social world (Haimes, 2006). Empirical research provides the data upon which normative judgments are made: Moral theories, informed by facts, judge practices. In this context, researchers collaboratively are actively engaged in exploring the dynamic interplay of psychological, social, cultural, cross-cultural, and biological factors in health, illness, and care; in studying the experiences, feelings, and behavior of patients and families, doctors and nurses; in describing and analyzing the attributes and impact of the hospital as a social world; and in observing and delineating the socialization process through which medical students were pro- gressively transmuted into physicians (Fox, 1999).

From Percival to the present day, medical ethics and its discourses always privilege professional medical perspectives. In striking contrast to medical ethics, bioethics is a multidisciplinary field addressing ethical issues in the biomedical sciences, as well as in health care, without privileging physicians' (or scientists') conceptions or discourses-hence bioethicists' insistence on a non-professional presence on hospital ethics committees and their emphasis on concepts like autonomy and respect for persons as a counterweight to professional authority. In the multidisciplinary context, members are united by the common purpose of analyzing, researching, studying, and/or attempting to address, mediate, and/or offer solutions, or resolutions to ethical problems arising in biomedical science and healthcare. The multidisciplinary nature and anti-elitist stance endemic to bioethics creates significant challenges to the professionalization process and is a factor in the cautious approach bioethics organizations have taken towards professionalization (Baker, 2009).

Interdisciplinary research is defined as bringing together different disciplines to focus on a circumscribed problem, but keeping the disciplines distinct. It is a mode of research by teams or individuals that integrates information, data, techniques, tools, perspectives, concepts, and/or theories from two or more disciplines or bodies of specialized knowledge to advance fundamental understanding or to solve problems whose solutions are beyond the scope of a single discipline or area of research practice. The virtue of this is that the strengths of one method may help overcome the limitations of another, while using two or more methods in any specific research project will help to build up a richer data set (Pickering, 2008). Researchers work as part of multidisciplinary teams, informing theory with data and orienting descriptive studies to help find solutions to knotty normative questions (Sugarman \& Sulmasy, 2010).

Interdisciplinary research takes bits and pieces from the contributing disciplines and integrates them in ways that produce a new conceptual framework. For instance biomedical research today would include experts from different specialties such as clinicians, social scientists, lawyers, epidemiologists and philosophers. In the bioethics landscape, a whole range of different disciplines engage with a research question. The field is comprised of practitioners from medicine, philosophy, theology, law, nursing, social psychology, epidemiology, health services research, medical history, medical anthropology, medical sociology, economics and related fields all working in the field of bioethics (Sugarman \& Sulmasy, 2010). Bioethics entertains relationship with literature, history, religion, philosophy, law, economics, the social sciences and policy.

Interdisciplinary research approach in bioethics emphasizes the use of empirical methods to study the role of empirical research in bioethics, and how empirical findings could be used in ethical analysis. The empirical turn in bioethics has brought the methods of the human and social sciences into an explicit dialogue with those of normatively focused analytic applied philosophy (Emmerich, 2011). Researchers may use empirical or hypothesis-based methods (similar to science) and theoretical or principled-based methods (as in traditional philosophy). Researchers using empirical methods in doing normative bioethics wish to understand "how knowledge about what is can be helpful in deducing what ought to be done?" Empirical methods in bioethics investigate the ways in which data generated by empirical research can be relevant to bioethical thinking and 
regulation concerning health care and human use of biotechnology (Holm \& Jonas, 2004). Due to the methods, empirical research has grown substantially as a tool for normative ethics and public policy. It has helped elucidate the magnitude of specific issues, explore the beliefs and experiences of stakeholders, and counter erroneous empirical claims of existing policy positions. Empirical approach seeks to collect empirical data needed to shed light on a bioethical problem, or it attempts to stand outside the discipline in order to study the field itself. Projects use either qualitative or quantitative social science methodology to collect data needed to make persuasive bioethical arguments.

Qualitative research is used broadly to refer to text-based, non-statistical methods. Generally, qualitative methods involve asking open-ended questions of a relatively small number of informants to gather data to address particular research questions. Although qualitative data can be gathered to test hypotheses, more typically the research questions addressed by qualitative methods are discovery, descriptive, and explorative. Qualitative methods expand understanding of what types of experiences, beliefs, or attitudes exist. Meanwhile, quantitative methods are most appropriate when some previous understanding of phenomenon exists; they are used to estimate the proportion of individuals with particular experiences, beliefs, or attitudes and to explore statistical associations between these experiences, beliefs, and attitudes (i.e., outcomes) and various socio-demographic characteristics or other hypothesized predictors of such outcomes. Accurate estimates generally require conducting research with larger numbers of respondents (Taylor, Hull, \& Kass, 2010).

Yet, decision making in bioethics is deeper and more than just the methods of qualitative and quantitative inquiry. The fact is ethical deliberation and explanations go deeper than simply providing interesting data for bioethicists to examine. Bioethicists test to what extent the different claims made by practitioners "that something is right" are actually justifiable, or are sound, consistent, and based on good reasons. It is for this reason that we must continue to examine such research with caution and use deconstruction and deliberation to spot out fuzzy thinking and demolish bad arguments before establishing it validity. We must spot out the logical fallacies, disambiguate the meaning of propositions, criticize definitions, map the logical structure of arguments, and pinpoint their missing premises and flawed inferences. We must be attentive to the fact that research is done rigorously, we must scrutinize conclusions for their soundness, and we must be vigilant that we do not inadvertently use empirical findings to justify practices that are morally objectionable (Braddock, 2010).

Bioethics research recognizes the fact that the empirical method has its place since it can help sharpen and accurately focus the dimensions of an ethical challenge or bring clarity to core premises and assumption of an argument, but rigor can come in many forms. Although carefully conducted empirical studies can help elucidate facts, there is need to carefully scrutinize research findings to ensure that researchers do not conflate "is" with "ought" or "the naturalistic fallacy" which flows from the observation that the moral rightness of actions cannot be justified simply by the observation that such acts are committed, no matter how common. Also, empiricism should not be confused with good academic work. It is important to appreciate that many of the best designed empirical studies will fail to answer important value questions and that bioethics without such questions is really, nothing at all. If all our studies resulted in an objective outcome, even success would mean failure because we had limited our inquiry to questions that would result in bite-sized answers (Fins, 2010).

However, the interdisciplinary approach to research poses challenges to bioethics as different experts in the field attempt to propose solutions. John Coggon writes that, there can be difficulty in finding sound resolution between the competing perspectives. Where fundamentals differ, we face apparent deadlock, with theorists seemingly able only to talk across each other. He further writes that what becomes clear is the great unlikelihood of finding a methodology for bioethics. It comprises too many analysts from too many backgrounds (Coggon, 2011). Which discipline (or method) would be capable of doing which job? And how can different approaches and their contributions be integrated without stepping into an "anthology trap" of just referring to a variety of historically developed methods (from consequentialism to deontology, virtue or discourse ethics, care or narrative approaches) one after the other, leaving people simply faced with the different results and thereby jettisoning the clarifying and guiding role of ethical investigation? (Rehmann-Sutter, Düwell, \& Mieth, 2006).

What is the state of the art of interdisciplinary scholarship, education, and service in bioethics in Africa? With the increasing use of empirical method in bioethics and the quest for more objective evidence through qualitative methods, numbers, it seems, have replaced values, and because of that, much of our deliberations have become impoverished. Further still, there is need to make clear the boundaries that ought to guide interdisciplinary research in bioethics and ensure that the autonomy of research disciplines are always respected and understood in authentically interdisciplinary research. Moreover, interdisciplinary research is a challenging and complex domain where Africa is still to introduce and integrate in its programs. Its interdisciplinary nature necessitates mastering an extremely broad area of knowledge which bioethics in Africa still needs to improve its scholarly standards. Its complex, indeterminate, interdisciplinary and multidisciplinary character creates conceptual and theoretical challenges to it teaching, as well as, the need to define it object and scope.

The challenge of combining the empirical and theoretical approaches of research in Africa and for African researchers to integrate interdisciplinary approaches to resolving dilemmas in scientific research and their application is the most daunting task for researchers within the African context. Also, the challenge to conflate is with ought to this methodological mix remain the vital problem that burden research in the interdisciplinary context. African institutions have not yet develop the theoretical and normative frameworks for assessment-making and evaluation of interdisciplinary research that integrates different methodologies. Additionally, assessment faces serious challenges in providing reliable, well-communicated, and policyneutral but policy-relevant aggregation of knowledge in science, technology and medicine. Bioethics in Africa is still largely empirically uninformed as it is still limited in terms of approach and methodology in this interdisciplinary or multidisciplinary nature of the field and the challenges of doing research with different values and research methodologies. There is little systematic treatment of this area from a cross-disciplinary and cross-cultural perspective. Africa still lacks the technical know-how, human capacity, knowledge on various research methods or approaches of teaching bioethics and sound training 
in different disciplines which can make interdisciplinary research more productive and relevant for bioethics in the continent.

\section{Relevance of Teaching Bioethics in Africa}

The purpose and aims of education or of any educational initiative are to increase and improve human knowledge, virtue and responsibility. Bioethics education is an essential tool for character development, knowledge, skills and behavior that serves to enrich students' moral sensibilities. Its pedagogic goals are to enable students identify conflicts of values, increase their sensitivity to morally perplexing issues, improve their understanding of their own values, and to deal more openly with bioethical dilemmas. It offers better reasoned responses, and provides the context to explore more thoroughly the implications of different courses of action before taking action. Studies have demonstrated that certain outcomes improve as a consequence of bioethics education. The existing literature shows that learner awareness, attitudes, knowledge, confidence, decision making, and, to some extent, moral reasoning improve with educational interventions. As such, teaching bioethics becomes a moral imperative for Africa as long as new breakthroughs in science, technology and medicine continue to offer new possibilities and capabilities to humans to alter their lives, environment and improve their well being.

To many of these scientists, moral objections to their works are not valid especially as science by definition is neutral, so any moral judgment on it simply reflects scientific illiteracy. However, in spite of the confidence in the power of modern scientific technology today and the claim to it value neutrality, awareness of its ambivalence has grown considerably. Humanity is becoming more conscious of the fact that innovations are potentially harmful or can pose serious risks which raise serious ethical questions about their use, the protection of members of society from harm and to secure the conditions of its preservation that confront Africans every day. New developments also create situations for Africans to make serious decisions about their lives. Should they allow this or that kind of innovation without understanding the potential harm from the benefit? How can they understand and evaluate costs and benefits associated with scientific advances?

There is also the realization that certain innovations are becoming unpalatable and leading to moral panic on science or the fear of a "slippery path" which is if science is not reined in now, it will cross red lines in the future. As such, something might be scientifically possible but unethical to do and this calls for increased prudence and caution. Also, there is the realization that there are no standards to regulate and guide the progress and this creates a need to reinvigorate standards for teaching research ethics within Africa. Confronted with these challenges, the aim of bioethics is to reflect on the implications of progress before it is too late to do so. Another challenging issue is the fact that African students are seldom exposed to teachings and courses addressing ethical questions and principles which implies that they lack the skills to anticipate potential harm to their lives and society that can arise from scientific activities or research.

Furthermore, in spite of the exponential growth bioethics education is experiencing in the world scene today, there is a noted low growth of bioethics in Africa as bioethics education, teaching and understanding of its processes and challenges to our lives and communities are still sub-marginal. There is a lack of infrastructures to match today's progress in bioethics; a general lack of training to bring about leadership and lack of programs to foster the development and growth of bioethics education in Africa. This situation is unfortunate, considering that various research that aim at finding solutions to the multiple problems affecting our communities and the need to address and assess these problems in ethical terms are of crucial importance to us.

Further still, when most research is conducted by researchers from developed countries and in Africa in particular, the social, cultural and economic context of the research has a major bearing on ethical conduct of research. African views on the ethics of this research are neither sufficiently developed nor heard. In most debates both sides are represented almost exclusively by researchers and bioethicists from the developed world, even though this is an ethical issue of crucial importance to Africa. To confront and overcome these challenges, African countries need to develop human, institutional and infrastructural capacities to enable them address optimally the new megatrends in medical technologies and the bioethical challenges created. Africa needs experts to combat most ill informed challenges facing the continent in the face of challenging diseases and limited health facilities. There is the need to design courses and introduce their teaching at undergraduate and graduate levels in universities so that students are exposed to current bioethical issues which enable them acquire tools to address ethical issues in professional life and raise their awareness concerning responsible conduct of research (Turrens, 2005).

Since we must determine what is acceptable or not, in the light of our values and cultures, bioethics education provides a real-world context for introducing and underscoring the "need to know". Knowledge of bioethics can inspire students to gain a deeper understanding of scientific facts so they can make well-reasoned ethical arguments. The most dominant approach to teaching bioethics to students in the humanities, social sciences and sciences has been founded on some combination of a philosophical approach and practical problem solving. This teaching approach is a dynamic balance between conceptual analysis and the concrete engagement of cases. In most contemporary work in medical ethics it is divided into three parts: ethical analysis and arguments of large-scale issues in science, practice and policy (such as consideration of the ethical issues concerning cloning or resource allocation); theoretical inquiry into the foundations of medical ethics; and practical analysis of particular dilemmas in clinical practice (Ashcroft, Parker, Verkerk, \& Widdershoven, 2005). In the philosophical approach, some versions of principles or duties, either deontological or utilitarian are used.

Meanwhile, other versions such as virtue, narrative, casuistry and feminist ethics are also utilized. In this approach, groups of students are provided the opportunity to research, analyze, discuss, and propose public policy on emerging topics in bioethics (Harwood, 2004-2005). The purpose is to develop in students the capacities for values clarification; Clarification of reasoning; Listening to others; Understanding human relationship; Promoting creativity; Strengthening moral conviction. The practical "case and issue" based approach is reinforced by the traditional healthcare teaching model in which knowledge is passed on through a series of case encounters (Liaschenko, Oguz, \& Brunnquell, 2006). Here activities are highly participatory and 
inquiry-guided as students are encouraged to integrate abstract concepts with concrete reality and to develop essential skills in critical reasoning. Small-group work and collaborative teaching involving bioethicists and clinicians are the effective strategies for case-based teaching. Brief lectures, short readings, casebased teaching sessions, discussion forums, and assignments constitute the teaching approaches. Also, students explore multiple possibilities/solutions and experience making decisions which sharpens their interpersonal, communication, and moral reasoning skills. This is justified by the fact that, morality is something that is learned through clarification of our values and application of these values to cases.

A careful study of the pedagogic approaches adopted in most medical faculties in universities and medical schools in Africa indicates that the "case and issue based" approach to teaching bioethics to medical students is still insufficiently developed. Much still need to be done to enable students learn the importance of demonstrating compassion, caring, and respect in their interactions with patients, families, and colleagues. Meanwhile non-physician medical ethicists or bioethicists do not form part of the teaching staff in these medical faculties and schools. There is an apparent lack of rigor as students are not encouraged to engage into lengthy or extended discussions about ethical principles and conflicting values at stake in the care of a patient. In most instances, the impression is that ethical thinking is a routine and mechanical business, which collapses into a vulgar utilitarianism over any other concern as ethics seems to have become excessively simplified. The medical literature on the ethics of the profession and ethical principles are neither expansive, nor current, and those students reading them are those who have a particular interest in the history of medicine.

This situation rarely invites critical inquiry into distinctions between what is customarily done and what ought to be done based upon standards, values, and priorities that reflect the larger society and not merely the insular perspective of the practitioners of the profession. In this light, bioethics education has made no major impact on the health care delivery systems in general in Africa. Additionally, coupled with defective healthcare systems, appalling infrastructures and inefficient healthcare management and paucity of new healthcare technologies, facilities and methods, healthcare education is largely beyond standards. The content of medical ethics and ethics education remain insufficient and questionable to the extent that upon graduation the delivery of medical care and kind of care administered to patients (the ability of doctors to care for their patients as individuals) and the relationship medical doctors entertain with their patients especially in the African context characterized by lawlessness is so sub-marginal. Medical education or medical ethics, and more particularly its inclusion in the medical school curriculum, still has to "come of age" in Africa.

Bioethics education and teaching are today gradually oriented towards forms of education through professionalism, in terms of virtue ethics, cultivating altruism, respect of the personality of the other, honesty and integrity, responsibility and dedication to the fulfillment of one's duties, as prominent virtues. In the last decade, dozens of ethics centers and programs devoted to "business ethics", "legal ethics", "medical ethics", and "ethics in public policy" have sprung up. These centers are designed to examine the implications moral principles have on our lives. The standard bioethics teaching scheme of classification which essentially attempts to carve up the field according to the schools of moral philosophy: Consequentialism, deontology, communitarianism, virtue ethics, feminist ethics, care ethics, and so forth. It was commonplace for anthologies used in bioethics courses to include a section on medical paternalism and its errors. For example, one of the first and most widely used anthologies, Moral Problems in Medicine, had a section devoted to paternalism with eleven selections. In addition, the first edition of Principles of Biomedical Ethics made medical paternalism a central focus (McCullough, 2011). Most teaching programs aim at introducing students to various normative and meta-ethical theories (cultural relativism, emotivism, subjectivism, utilitarianism, social contract, and Kantianism).

The most fundamental and surreptitious goal of bioethics education has been outlined as: to evacuate ethical decisionmaking of its ambivalence and discomfort, and to offer a set of best-practice guidelines to produce ethical "outcomes," to preempt lawsuits, and to safeguard the putative goodness of one's good conscience (Murray \& Holmes, 2009). The real struggle to arrive at an ethical outcome compels the direct participants to dig down into their underlying moral assumptions. They must bring to the surface what they find most valuable and most meaningful. As such, bioethics education aims to nurture the development of moral sensitivity, perception, judgment and capacity for action, which will sustain moral agency and ethical practice. The purpose of bioethics education is to provide information regarding bioethical issues and knowledge of those issues so as to raise students' level of awareness and sensitivity to ethical problems. It aims at enhancing students skills about normative ethical judgments and promote behavior change. Also, it is to teach students methods of reasoning and logical argument (Itai, Asai, Tsuchiya et al., 2006). It also aim to stimulate moral sensitivity, respect for the patient's autonomy, instead of the earlier paternalism, attainment of consent, development of analytical skills in moral reasoning and morally justified decision-making.

It enables students to be able to construct reasoned arguments to support their positions on the ethical and social impact of advances in science, technology and medicine. One of the intellectual skills expected is "recognizing the moral and ethical issues of investigations and appreciating the need for ethical standards and professional codes of conduct". The target in bioethics education is to enable students develop content knowledge and reflective processes that facilitate the exploration of morals or values analysis. It aim to develop in students skills for developing "informed choices" and to cultivate respect for persons, minimizing harms while maximizing benefits and fairness as they encounter and confront ethical choices in their daily living. Bioethics education can influence students to ground bioethics in human dignity, autonomy and ultilitarianism. Students develop competence in a kind of reasoning about ethical issues encountered in day-to-day practice. As observed by some teachers, competence in identifying ethical dilemmas in our own practice is also viewed as a manifestation of a successful ethics education.

Furthermore, the study of bioethics can encourage important critical thinking which develops a sense of responsibility and problem solving skills. Bioethics activities emphasize the importance of justification, a process of giving reasons for views. Critical thinking capacity is essential for empowering persons to cope with changing times and encourages active engagement in the deliberation of issues in the areas of medicine and biotechnology. It develops the ability to make well-informed and 
well-considered judgments, the ability to understand and evaluate arguments, the ability to make well reasoned decisions, and the tendency to be fair-minded. As Darryl Macer puts it: critical thinking should not only promote the creation of ideas but also the formation and adoption of humane moral values while treating patients, or while forming social decisions with regard to human health and life (Macer, 2008). It is a process that involves the analysis of concepts and arguments and the interpretation of concrete data or evidence, which requires capacities for self-criticism, moral imagination, and empathy (Memeyer, 2002).

As such, developing the capacity for critical thinking in students becomes a legitimate and valuable goal for teaching bioethics in various scientific fields and in the humanities and social sciences. It equips students with concepts, cases, fact sheets, and teaching strategies that will help them examine crucial questions and critically analyze problems in a more careful and nuanced way. The introduction of this process into higher educational system in Africa would train and empower a critical mass of African experts. However, the question of whether there exist experts in ethics or bioethics has been an issue of serious debate. Not only do many authors disagree on whether ethics expertise exists, they disagree on what it is.

A host of salient questions have been raised on the issue of ethics expertise and they include: 1) How does ethics expertise relate to morality and ethics in general? That is, does an ethics expert possess moral wisdom in the sense of knowing the truth about the right and the good? 2) What kind of training gives one ethics expertise? Is it only graduate school education in philosophy or theology? 3) What kind of political or legal authority does an ethics expert possess? If an ethics expert advises on government policy, are policy makers mistaken to override that advice? Would a bioethics consultant's expert opinion be sufficient to override the wishes of others, including the patient or family member? Even if that were illegal, would it be unwise, morally speaking? 4) How (apart from credentialing dependent on question 2) can the rightness of an ethics expert's opinion be assured? On what basis can it be challenged? (Rasmussen, 2005).

By expert in bioethics, it should be understood as those endowed with special and some normal faculties in an extraordinarily high dose. Experts in bioethics comprise those who have certain competences and mature knowledge of ethical theory, the relevant facts and moral codes in different societies and the ability to justify coherently moral judgments. They exhibit the qualities listed by Peter Singer: 1) ethicists are familiar with moral arguments, 2) they can infer correctly, 3) they are familiar with moral concepts 4) they are able to study moral problems more deeply and over more time than other people, 5) they have the ability to empathize with other people (Singer, 1972). Additionally, they have some self-awareness, which means they can discover and defeat their own prejudices.

However, they are not experts in the weak sense but experts in the strong sense. Bernward Gesang describes ethicists of the weak sense of expertise as those who have knowledge in certain areas, because they can justify their judgments well and because they have reached a certain level of education. Meanwhile, people are called experts in the "strong sense" if their judgments are correct with high probability and for the right reasons. They need not have a special quality of knowledge that the person on the street can never access. (Gesang, 2010). They are the persons to develop teaching programs and intro- duce bioethics in school curricula. Also, they have to engage students into critical thinking and active engagement or participation in shaping social policies. This will enhance student's ability to see the ethical dimensions of a given situation. The ability of students to distinguish an ethical question from other kinds of questions, such as legal, scientific, or personal-preference is crucial for bioethics education.

This goal of teaching bioethics is to raise the moral sensibilities or moral imagination of students to think about choices from a variety of viewpoints and interests, and to think on their own since conscious thinking and participation are the hallmarks of democratic citizenship (Kohlberg, 1981). Moreover, bioethics is in most Western countries a dynamic, multidisciplinary field with several dedicated journals, a national organization, and numerous centers and institutes. Yet in most African countries most of these instruments that give bioethics legitimacy are still lacking. To salvage this crucial problem, experts can train and encourage African researchers to write and publish books and initiate journals centered on African bioethics and in which works bringing out African approaches and specificities are published.

A conceptual framework for the introduction and teaching of bioethics at the undergraduate levels in universities in Africa would consist at addressing the following issues: What is ethics (descriptive ethics, normative ethics, analytic ethics or metaethics)? Make a distinction between what is often taken to be the three main theories of ethics - utilitarianism (or more broadly, consequentialism), deontology and virtue ethics. Develop understanding in communitarian ethics and values (African communitarian ethics) (Andoh, 2011), culturally relevant bioethics for Africa, the role of bioethics in medical education in Africa and intercultural bioethics. What is morality and how is morality distinct from ethics? What ethics is NOT:

Ethics is not the same as feelings: Feelings provide important information for our ethical choices. Some people have highly developed habits that make them feel bad when they do something wrong, but many people feel good even though they are doing something wrong. And often our feelings will tell us it is uncomfortable to do the right thing if it is hard.

Ethics is not religion: Many people are not religious, but ethics applies to everyone. Most religions do advocate high ethical standards but sometimes do not address all the types of problems we face (Velasquez et al., 2009).

Ethics is not following the law: A good system of law does incorporate many ethical standards, but law can deviate from what is ethical. Law can become ethically corrupt, as some totalitarian regimes have made it. Law can be a function of power alone and designed to serve the interests of narrow groups. Law may have a difficult time designing or enforcing standards in some important areas, and may be slow to address new problems.

Ethics is not following culturally accepted norms: Some cultures are quite ethical, but others become corrupt or blind to certain ethical concerns (as the United States was to slavery before the Civil War). "When in Rome, do as the Romans do" is not a satisfactory ethical standard.

Ethics is not science: Social and natural science can provide important data to help us make better ethical choices. But science alone does not tell us what we ought to do. Science may provide an explanation or facts for what humans are like. But ethics provides reasons for how humans ought to act. And just because something is scientifically or technologically possible, 
it may not be ethical to do it (Velasquez et al., 2009). Graduate program for bioethics education include: Research ethics, medical ethics, reproductive ethics, end-of-life ethics, medical law, clinical bioethics, moral reasoning, genetics, transplantation, neuroethics, pharmaceutical ethics, disability bioethics, animal biotechnology and environmental ethics.

From the above, it can be seen that ethics is not a set of specific, immutable, unchanging laws applied the same way today as a hundred years ago. Rather, ethics stem from values and beliefs whose expression continues to evolve as they are informed by advances in science, politics, art, culture, and society. New developments cause us to reconsider previously held assumptions, comparing them with our values and, at times, changing our notion of how those values should be expressed. Students are challenged to make a demarcation between ethics and other disciplines and to provide justification or reasons for their positions. Students' skills should be developed on the distinction between procedural and policy issues, foundational issues and substantive bioethical concepts, problems and dilemmas that constitute the field of bioethics.

Also, emphasis should be laid on the fact that in the professional development of bioethics in the past fifty years, a substantial body of knowledge has emerged. Such knowledge not only provides a global frame of reference for bioethical decision-making, it also provides information, analysis and clarification that will be useful for interpreting and discussing cases, problems and policies in specific cultural, religious and political contexts. Moreover, a case based approach, which is teaching to real life or by basing teaching on cases students can recognize from their own experience, or which they might encounter later on in their professional life, should be integrated in the teaching of bioethics in Africa.

\section{Challenges to the Teaching of Bioethics in Africa}

According to Catherine Myser, bioethics is currently taught around the globe. She writes that in developing and developed countries alike, educators are taking on the challenges of identifying and developing the most appropriate objectives, content, methods and assessment strategies to teach bioethics (Myser, 2001). Despite the fact that bioethics education has become an integral part of undergraduate and graduate teaching programs taught around the globe, in Africa, bioethics education and training programs in high schools, undergraduate and graduate levels are still lacking. Within Africa, bioethics is still seen as a new discipline and by nature interdisciplinary, and many of those to teach it still lack the training in the didactic approaches of the field.

In most African countries and educational system, the field is still considered new and bioethics education is underfunded and lacks national standards. This has constrained African government's capacity to introduce the teaching and sustenance of the discipline in school curricula. There is lack of resources for the academic formation of bioethicists. The various teaching activities are not coordinated, and there is a need for competent teachers and suitable teaching material. Bioethics education is given lip service but not substance as bioethics courses are often meager in content. This constitutes a serious barrier to the implementation, emergence and teaching of bioethics in schools and since the field is fairly new and remains underfunded, less effort has been expended in developing programs.
Furthermore, bioethics as an academic or professional discipline is a domain in which Africa is still lagging behind. Africa has very few trained bioethicists, bioethics is not taught in higher institutions of learning and there is no vibrant culture of bioethical discourse among philosophers, scientists and medical practitioners. There is a lack of critical thinking in the field in Africa as no academic dissertations or theses are being examined in the field. Karori Mbũgua laments this as he writes that: "Unfortunately academic bioethics, like professional philosophy, is still largely foreign in most African countries. Indeed, despite the rapid growth of bioethics research centers especially in Europe and North America, there are still relatively few places in Africa where one can obtain formal bioethics education even at the certificate level'(Mbũgua, 2009). The field's development in this area has been very sluggish as bioethics is not yet an escalating tradition of thought and talk by ways of teachings in classrooms, publications in typically African journals and conferences in Africa.

Consequently, there are no academic resources to enable African students learn how to identify ethical issues and to discuss them productively with others. At both the high schools and college levels there exists no major teaching tools and programs to stimulate the moral imagination of students or help students recognize moral issues. Most African students still lack the means and methods to understand what kinds of questions can be raised by this or that dilemma? Who are the participants in the dilemma? What are the points of conflict? What things have to be considered in making a choice? Who is affected by the decisions? What ethical problems does the decision seem to raise? There are no guides to help students analyze key moral concepts and principles, to help students deal effectively with moral ambiguity and disagreement so as to stimulate students' sense of responsibility, virtue and obligation.

The implication is for the African community welfare and well-being. If Africans are not taught the importance of bioethics issues for their community, they may easily be exploited, their legal rights of self determination may be disregarded, and their experience of health care will be less than optimal. The risk is that bioethics may come to be viewed as marginal and therefore expendable (Moore, 1996). A careful survey would reveal that most African governments have not yet taken the commitment to set up and strengthen ethical standards and bioethics bodies in their respective countries. Meanwhile, there is need to create and encourage formal teaching of bioethics in universities and post university education that deal with research on human subjects. The need to provide an excellent environment for discussion of the principles behind moral reasoning and to create an ethical learning climate, which can help undergraduates acquire tools to address ethical issues in professional life. Creating an ethical learning climate requires cultural change and paying serious attention to role modeling in the learning environment and implementing policies and processes to ensure a learning climate conducive to ethical development. There is the necessity to put into place programs of training and teaching on ethics, bioethics and right to health in all academic and professional programs (health sciences, social and human science and technology).

The future of bioethics in Africa is bleak as bioethics is not taught in many higher educational systems of learning. Africa in this century still lacks professionals, experts, professors of bioethics, the institutions, infrastructures and the critical mass of African experts to address the current issues of bioethics 
from typically an African background to bring out African specificities and approaches. The implication that this has on the teaching of bioethics within the continent is that Africans lack the capacities, skills and strategies to recognize ethical issues, lack moral imagination, cannot use analytical skills and would not develop a sense of moral obligation and responsibility to confront the new challenges in science, technology and medicine. Also, lack of these skills means that they lack the ethical capacities to identify dilemmas or to understand dilemma situation and how to explore the ethical values and concepts that explain why the dilemma is a dilemma.

Meanwhile, in most Western countries, bioethics gained legitimacy since the early 1970s and there has been an increasing trend of bioethics centers becoming academic departments. The professionalization of bioethics has taken it from the academic margins to the center, and with this development has come all of the trappings of traditional academics, such as tenure, degree programs, professional conferences, and academic journals. Additionally, beginning in the 1980s, departments of bioethics, depending on their configuration, offer traditional undergraduate or graduate courses, undergraduate majors or concentrations, graduate degrees (usually master's degrees), undergraduate medical school ethics training, and/or residency ethics training.

In spite these developments, in Africa, bioethics is not yet a legitimate discipline as no concrete steps have been taken to institute the teaching of bioethics in institutions of learning and no major attempts to shape the identity of bioethics vis-a-vis other disciplines, for example, medical ethics which has occupied centre stage of medical practice. Despite greater acquaintance with bioethics as an academic discipline and the recognition of bioethics as an autonomous discipline, most African universities have not yet include the teaching of bioethics courses in their undergraduate and post-graduate curricula. In addition, no concrete measures and efforts have been undertaken for the creation of research centers destined exclusively to conduct research in bioethics in African countries. The absence of research centers in bioethics implies that researchers have no avenues or structures to group themselves around common topics and for discussions with new researchers. Currently, there are very limited platforms for bioethicists to interact and share ideas and best practices.

The most fundamental and complex challenge to the teaching of bioethics in Africa revolves around understanding the nature and the varieties of bioethics. The fact that bioethics in Africa is a discipline without a well-defined subject matter that could pass the muster of serious critical academic evaluation. There is still a lingering uncertainty about its purpose and value. Edmund Pellegrino summarizes it in the following questions: How much of "bioethics" is biology, how much is ethics, and how much is in the domain of the humanities or social sciences? How do the many disciplines that now claim a role in moral deliberation relate to each other? Where does philosophical ethics fit in the expansive visions of bioethics that are now fashionable? Is it merely one discipline among many, or can it make some claim to the role of primusinter pares? If bioethics is, indeed, an interdisciplinary exercise, how inclusive and how diversified should bioethics be? How much of bioethics should be ethics? (Pellegrino, 2002).

The field has no dominant methodology, no master theory or its own ethical principles since it has borrowed pieces from philosophy, theology, fragments of law and social sciences. Furthermore, it is argued that: Still, many students, and even some of those who have graduate degrees in the specific disciplines that contribute to bioethics, remain unclear just what "bioethics" means, what bioethicists do, how one prepares for practice in the field, and the value of the profession (Miller, Fletcher, \& Humber, 2003). Yet, it continues to be understood, taught and applied as principlism, and its experts continue to flood the halls of health care facilities, courts, congress and government departments and agencies in most central countries. Bioethical expertise is widely sought in the framing of public and institutional policy. Bioethicists regularly provide testimony as expert witnesses in courts of law. They present themselves as experts of moral rationality and principles of moral probity, including permissible standards of evidence and inference (Peppin \& Cherry, 2005).

Furthermore, bioethics as John D. Arras indicates is not a unitary "discipline" with its own distinctive methods and credentialing institutions. Bioethics is not a monolithic entity or activity as there are varieties of bioethics. There is clinical bioethics, which amounts to the deployment of bioethical concepts, values and methods within the domain of the hospital or clinic. There is policy-oriented bioethics where the bioethicist cum policy analyst is called upon to assist in the formulation of policies that will affect large numbers of people. There is bioethics as a theoretical pursuit mostly in the academy, where within the academic domain the relationship between philosophical-religious theory and bioethics are explicitly discussed (Arras, 2003).

Discussions in a clinical bioethics setting often revolves around philosophically charged subjects, such as informed consent, competency, the right to refuse life-sustaining treatments, and so on; but the discussions themselves are rarely explicitly philosophical. Effective ethics training here is done during medical school and residency training. Medical students and doctors are trained to address effectively the disclosure of bad news, informed consent, confidentiality, dishonesty, research ethics, end-of-life care, resource allocation and the like, the doctor must recognize situations as an ethical dilemma; possess the relevant knowledge of norms, laws and policies; analyze how this knowledge applies to the situation at hand; and demonstrate the skills needed to communicate and negotiate this situation in practice (Singer, 2003).

At a time when the concerns of science and society are increasingly intermingled and when much scientific research occurs without ethically informed or effective regulations, Africans can hardly afford not to pay attention to these questions. To hope that someone will solve these very real problems for us is to abandon our lives and destiny at the doorstep of harm. It is our responsibility to choose wisely in our use of promising technologies. We need to be reminded that when it comes to ethics, passively allowing something to happen is morally not different than actively making it happen. There is a need for a radical rethinking and re-invention of the fields' nature, purpose, scope, approaches and priorities within Africa. The challenge is that bioethics has to be practically relevant, that is, the individual reflections of African bioethicists must primarily be geared towards resolving bioethical dilemmas confronting Africa today. Also, much still needs to be done to inspire and motivate bioethics teachers in their work, and to enter deeper into the issues of how best to teach bioethics. In this light, Africa has to develop standards to certify expertise in clinical ethics, research ethics, and scientific integrity, and to develop codes of ethics governing not only clinical ethics consultation 
but the full range of bioethical activities. The strengthening of bioethics education and research and the raising of public awareness of bioethical issues in Africa must be given priority. Appropriate structures for deliberation and action on bioethical issues must also be put in place.

However, there have been global efforts to strengthen and enhance bioethics capacity in Africa. Research ethics training programs have successfully been initiated by the US Fogarty Bioethics Training Program, African Malaria Network Trust (AMANET), the European and Developing Countries Clinical Trials Partnerships, the UK Welcome Trust, have been building capacity in Africa. Yet, the major challenge is for African governments to initiate their own bioethics courses and teaching programs in their respective countries and institutions. Till date, no major efforts have been undertaken to introduce the teaching of bioethics in African institutions by Africans themselves, as such, more efforts are required to raise awareness on issues and trends in bioethics. The need to create awareness on issues concerning responsible conduct of research and develop capacity for training of academic faculty, clinicians, researchers, government health ministry officials, NGOs, the media, traditional leaders and community representatives. More efforts are required towards increasing continent-wide awareness about ethical issues in biomedical practice and research through ethics conferences, workshops, national bioethics conferences, the public media and Non-Governmental Organizations (NGOs) (Tamidayo, 2004).

There is need to train experts who can look for means and methods that work to enable Africa define her priorities and achieve her goals in bioethics. Also, to bring in leadership and expertise that would enable Africa develops her values that may guide policies and practices in science and technology, as well as identify pitfalls bioethicists in Africa must avoid. The major challenge is that nothing concrete is done by African governments to confront the reality of these existential dilemmas that threaten the development and teaching of bioethics in Africa. It seems African governments are still "turning a blind eye" to the development and the implementation of strategies to enhance the teaching of bioethics in Africa. The phrase "to turn a blind eye" means to deliberately refuse to acknowledge something that one knows to be true (Cheshire, 2011).

When human condition and prospects face challenges from scientific undertakings, when ethical principles are improper for Africa, when the means and methods to teach or introduce the teaching of bioethics are insufficient, when Africa lacks experts and trained professionals, when Africa lacks the human, institutional and infrastructural capacities in bioethics, turning a blind eye to these issues that constitute the major challenges to the progress of bioethics is tantamount to destruction. Many of the issues that characterize the development of bioethics today concern efforts to avoid turning a blind eye to the new megatrends and breakthroughs in science, technology and medicine. The relevance of bioethics to Africa is of cardinal importance and ignoring it would ultimately lead to disaster.

\section{Conclusion}

Bioethics is one of the most flourishing disciplines in the world and there has been an increasing demand for the introduction and teaching of bioethics courses in schools and universities. However, although the list of immoral research is increasing and problems created are outpacing ethical decision making, bioethics education is not yet flourishing in Africa. The major challenge today is the institution of the teaching of bioethics in African universities and the legitimation of the discipline as a scholarly field of learning, which constitutes an urgent moral imperative for African governments. Bioethics education becomes a moral imperative for Africa as long as new scientific breakthroughs create complex moral challenges and moral dilemmas to their lives, well-being and welfare. The necessity to develop bioethics programs and initiate its teaching at the undergraduate and graduate levels in universities of Africa is of utmost urgency as this would train and empower a critical mass of African experts who can navigate moral vulnerabilities and remain morally intact, evaluate and confront the dilemmas created by the new wave of scientific research.

As such, effective bioethics education and teaching in Africa would consist of looking for means and methods that empower capacities of communities in African countries to understand the challenges of research (risks and benefits) and to respond positively to these challenges to their lives. Also, there is a need to re-enforce and strengthen the capacities of Research Ethics Committees to function optimally. It consists of building research institutions in universities, high schools and professional centers to train and empower future experts, professionals and leaders to empower a critical mass of African intellectuals. It encourages the publication of books and developing of African journals of bioethics that encourage the publication of ideas and issues on African bioethics specificities, approaches and peculiarities. There is a need to encourage the organization of conferences, seminars, workshops that train capacities and exchange of ideas on moral views and that stimulate academic discussions. It develops solid partnerships with other bioethics institution, organization, structures and nations. Moreover, educating the public is also critically important as we must rediscover the values of bioethics and re-learn the importance of the intellectual and scientific thought that is central to the best practice of bioethics.

\section{REFERENCES}

Andoh, C. (2011). Bioethics and the challenges to its growth in Africa. Open Journal of Philosophy, 2, 67-75. http://dx.doi.org/10.4236/ojpp.2011.12012

Arras, J. (2003). The owl and the caduceus: Does bioethics need philosophy? In F. G. Miller, J. C. Fletcher, \& J. M. Humber (Eds.), The nature and prospect of bioethics: Interdisciplinary perspectives. Totowa, NJ: Humana Press Inc.

Ashcroft, R., Parker, M., Verkerk, M., \& Widdershoven, G. (2005). Philosophical introduction: Case analysis in clinical ethics. In R. Ashcroft, A. Lucassen, M. Parker, M. Verkerk, \& G. Widdershoven (Eds.), Case analysis in clinical ethics (p. 1). Cambridge: Cambridge University Press. http://dx.doi.org/10.1017/CBO9780511545450

Baker, R. (2009). In defense of bioethics. Journal of Law, Medicine \& Ethics, 83-92. http://dx.doi.org/10.1111/j.1748-720X.2009.00353.x

Braddock, C. (2010). Empirical methods in bioethics: A cautionary tale. Annals of Internal Medicine, 152, 396-397.

http://dx.doi.org/10.7326/0003-4819-152-6-201003160-00011

Cheshire, W. (2011). Turning a BLIND Eye: An ethical assessment. Ethics and Medicine, An International Journal of Bioethics, 27, 1.

Coggon, J. (2011). On Method and resolution in philosophical bioethics. Cambridge Quarterly of Healthcare Ethics, 20, 159-163. http://dx.doi.org/10.1017/S0963180110000800

Emmerich, N. (2011). Literature, history and the humanization of bioethics. Bioethics, 25, 112-118. http://dx.doi.org/10.1111/j.1467-8519.2010.01818.x

Fins, J. (2010). The humanities and the future of bioethics education. 
Cambridge Quarterly of Healthcare Ethics, 19, 518-521. http://dx.doi.org/10.1017/S0963180110000551

Gesang, B. (2010). Are moral philosophers moral experts? Bioethics, 24, 153-159. http://dx.doi.org/10.1111/j.1467-8519.2008.00691.x

Haimes, E. (2006). What can the social sciences contribute to the study of ethics? Theoretical, empirical and substantive considerations. In C. Rehmann-Sutter, M. Düwell, \& D. Mieth (Eds.), Bioethics in cultural contexts (Vol. 28, pp. 275-298). The Netherlands: Springer. http://dx.doi.org/10.1007/1-4020-4241-8 20

Harwood, K. (2004-2005). Essays on teaching excellence. Toward the Best in the Academy. Teaching Bioethics through Participation and Policy-Making, 16.

Holm, S., \& Jonas, M. (2004). Engaging the world: The use of empirical research in bioethics and the regulation of biotechnology. Amsterdam: IOS Press.

Itai, K., Asai, A., Tsuchiya, Y., Onishi, M., \& Kosugi, S. (2006). How do bioethics teachers in Japan cope with ethical disagreement among healthcare university students in the classroom? A survey on educators in charge. Journal of Medical Ethics, 32, 303-308. http://dx.doi.org/10.1136/jme.2004.011577

Kohlberg, L. (1981). Essays on moral development. Vol. I: The philosophy of moral development. New York: Harper \& Row.

Liaschenko, J., Oguz, N., \& Brunnquell, D. (2006). Critique of the "tragic case" method in ethics education. Journal of Medical Ethics, 32, 672-677. http://dx.doi.org/10.1136/jme.2005.013060

Macer, D. (2008). Moral games for teaching bioethics. UNESCO Chair in Bioethics, Haifa, Isreal.

Mbũgua, K. (2009). Is there an African Bioethics? Eubios Journal of Asian and International Bioethics, 19, 4.

McCullough, L. (2011). Was bioethics founded on historical and conceptual mistakes about medical paternalism? Bioethics, 25, 66-74. http://dx.doi.org/10.1111/j.1467-8519.2010.01867.x

Memeyer, R. (2002). What conception of moral truth works in bioethics? Journal of Medicine and Philosophy, 27, 403-416. http://dx.doi.org/10.1076/jmep.27.4.403.8611

Miller, F., Fletcher, J., \& Humber J. (2003). The nature and prospect of bioethics: Interdisciplinary perspectives. Totowa, NJ: Humana Press Inc. http://dx.doi.org/10.1385/1592593704

Moore, J. (1996). Bioethics programs' future uncertain. Modern Healthcare, 26, 20.

Murray, S., \& Holmes, D. (2009). Critical interventions in the ethics of healthcare. Challenging the Principle of Autonomy in Bioethics. England: Ashgate Publishing Limited.

Myser, C. (2001). How bioethics is being taught: A critical review. In
H. Kuhse and P. Singer (Eds.), A companion to bioethics (p. 485). Oxford: Blackwell Publishing.

Pellegrino, E. (2002). Bioethics as an interdisciplinary enterprise: Where does ethics fit in the mosaic of disciplines? In R. A. Carson, \& C. R. Burns (Eds.), Philosophy of medicine and bioethics a twenty-year retrospective and critical appraisal (Vol. 50). Dordrecht: Kluwer Academic Publishers. http://dx.doi.org/10.1007/0-306-48133-2 1

Peppin, J., \& Cherry, M. (2005). The annals of bioethics. Regional perspectives in bioethics. Lisse: Swets \& Zeitlinger Publishers.

Pickering, M. (2008). Research methods for cultural studies (p. 5). Edinburgh: Edinburgh University Press.

Priaulx, N. (2011). Vorsprungdurch technik: On biotechnology, bioethics, and its beneficiaries. Cambridge Quarterly of Healthcare Ethics, 20, 174-184. http://dx.doi.org/10.1017/S0963180110000824

Rasmussen, L. (2005). Ethics expertise: History, contemporary perspectives, and applications (p. 3). Dordrecht: Springer.

Rehmann-Sutter, C., Düwell, M., \& Mieth, D. (2006). Bioethics in cultural contexts (p. 2). Dordrecht: Springer. http://dx.doi.org/10.1007/1-4020-4241-8

Renee, F. (1999). Is medical education asking too much of bioethics. Daedalus.

Schaller, B. (2008). Understanding bioethics and the law: The promises and perils of the brave new world of biotechnology. Westport: Praeger Publishers.

Singer, P. (1972). Moral experts. Analysis, 32, 115-117. http://dx.doi.org/10.1093/analys/32.4.115

Singer, P. (2003). Strengthening the role of ethics in medical education. Canadian Medical Association Journal, 168, 854-855.

Sugarman, J., \& Sulmasy, D. (2010). Methods in medical ethics (p. 3). Washington DC: Georgetown University Press.

Sugarman, J., \& Sulmasy, D. (2010). Methods in medical ethics (p. 6). Washington DC: Georgetown University Press.

Tamidayo, O. (2004). Enhancing the African bioethics initiative. BMC Medical Education, 4, 21. http://dx.doi.org/10.1186/1472-6920-4-21

Taylor, H., Chandros Hull, S., \& Kass, N. (2010). Qualitative methods. In J. Sugarman, \& D. Sulmasy (Eds.), Methods in medical ethics (p. 193). Washington DC: Georgetown University Press.

Turrens, J. (2005). Teaching research integrity and bioethics to science undergraduates. Cell Biology Education, 4, 334. http://dx.doi.org/10.1187/cbe.05-03-0068

Velasquez, M. et al. (2009). A framework for thinking ethically in issues. Ethics, 1. 